\title{
Axillary Recurrence After a Tumor-Positive Sentinel Lymph Node Biopsy Without Axillary Treatment: A Review of the Literature
}

\author{
Claire M. T. P. Francissen, MD ${ }^{1}$, Pim J. M. Dings ${ }^{1}$, Thijs van Dalen, $\mathbf{P h D}^{2}$, Luc J. A. Strobbe, $\mathbf{P h D}^{3}$, \\ Hanneke W. M. van Laarhoven, $\mathbf{P h D}^{4}$, and Johannes H. W. de Wilt, $\mathbf{P h D}^{1}$ \\ ${ }^{1}$ Department of Surgery, Radboud University Nijmegen Medical Centre, Nijmegen, The Netherlands; ${ }^{2}$ Department of \\ Surgery, Diakonessenhuis, Utrecht, The Netherlands; ${ }^{3}$ Department of Surgery, Canisius Wilhelmina Hospital, Nijmegen, \\ The Netherlands; ${ }^{4}$ Department of Medical Oncology, Radboud University Nijmegen Medical Center, Nijmegen, \\ The Netherlands
}

\begin{abstract}
Background. Sentinel lymph node biopsy (SLNB) has become standard of care as a staging procedure in patients with invasive breast cancer. A positive SLNB allows completion axillary lymph node dissection (cALND) to be performed. The axillary recurrence rate (ARR) after cALND in patients with positive SLNB is low. Recently, several studies have reported a similar low ARR when cALND is not performed. This review aims to determine the ARR when cALND is omitted in SLNB-positive patients.

Methods. A literature search was performed in the PubMed database with the search terms "breast cancer," "sentinel lymph node biopsy," "axillary" and "recurrence." Articles with data regarding follow-up of patients with SLNB-positive breast cancer were identified. To be eligible, patients should not have received cALND and ARR should be reported.

Results. Thirty articles were analyzed. This resulted in 7,151 patients with SLNB-positive breast cancer in whom a cALND was omitted (median follow-up of 45 months, range 1-142 months). Overall, 41 patients developed an axillary recurrence. 27 studies described 3,468 patients with micrometastases in the SLNB, of whom $10(0.3 \%)$ developed an axillary recurrence. ARR varied between 0
\end{abstract}

(C) The Author(s) 2012. This article is published with open access at Springerlink.com

First Received: 30 July 2011;

Published Online: 14 August 2012

C. M. T. P. Francissen, MD

e-mail: clairefrancissen@ hotmail.com and $3.7 \%$. Sixteen studies described 3,268 patients with macrometastases, $24(0.7 \%)$ axillary recurrences were seen. ARR varied between 0 and $7.1 \%$. Details regarding type of surgery and adjuvant treatment were lacking in the majority of studies.

Conclusions. ARR appears to be low in SLNB-positive patients even when a cALND is not performed. Withholding cALND may be safe in breast cancer selected patients such as those with isolated tumor cells or micrometastatic disease.

Since the 1990s, the sentinel lymph node biopsy (SLNB) has become the standard staging procedure for patients with invasive breast cancer. ${ }^{1}$ According to the current treatment guidelines, treatment of the axilla in case of a negative SLNB can be safely omitted. ${ }^{2}$ A positive SLNB indicates that completion axillary lymph node dissection (cALND) has to be performed. ${ }^{3}$ In case of four or more positive lymph nodes in the dissection specimen, adjuvant radiotherapy of the supra- and infraclavicular lymph nodes is indicated. ${ }^{4}$ Axillary radiotherapy is possibly an appropriate alternative for CALND. In the AMAROS trial cALND and axillary radiotherapy were compared; the main objective was to show equivalent locoregional control and reduced morbidity after radiotherapy. The final results of this trial have not yet been established. ${ }^{5,6}$ Although a cALND not only provides additional prognostic information, it could also optimize regional control and potentially improve overall survival. ${ }^{3}$ However, in $15-20 \%$ of the cases, a cALND leads to long-term complications such as pain, paresthesia due to intercostobrachial nerve injury, impairment of the shoulder function, or lymphedema. ${ }^{7,8}$ 
The axillary recurrence rate (ARR) after a cALND has been performed in patients with a positive SLNB is low. Recent publications show rates that vary between 0.2 and $0.9 \%$ for micrometastatic disease of the sentinel lymph node (SLN) and around $1.0 \%$ in case of macrometastatic disease. $^{9-11}$ These results are comparable with results from older studies in which all patients had been treated with ALNDs. ${ }^{12}$ Patients with positive axillary lymph nodes are usually treated with adjuvant systemic therapy: hormone therapy, chemotherapy or both. Although this might be an important factor for the low recurrence rate in the axilla, in case of breast conservative treatment radiotherapy itself on the breast is considered an important reason for a low ARR.

Recently, several studies in patients with a positive SLNB who predominantly underwent breast conservative treatment have reported a low ARR when cALND had not been performed. ${ }^{13-16}$ A prospective randomized trial (ACOSOG Z0011) tried to investigate whether cALND could safely be omitted in these patients. The trial was closed early as a result of slow accrual. The slow accrual probably implies that in daily practice there is still concern about the safety of omitting a cALND. Because interest is growing in omitting a cALND even if the SLNB is positive, this systematic review article aims to determine the ARR after a cALND has been omitted in SLNB-positive patients.

\section{METHODS}

\section{Literature Search}

A literature search was performed in the PubMed database using the search terms "breast cancer," "sentinel lymph node biopsy," "axillary" and "recurrence." Only articles published in the past ten years and in the English language were considered. References from the selected articles were used to complete the search. Two reviewers (C.F. and P.D.) independently performed the search; potentially relevant articles were selected on the basis of the title and abstract.

\section{Review Inclusion and Exclusion Criteria}

Articles with data regarding the follow-up of in cohorts a prospectively or retrospectively analyzed cohort of patients with SLNB-positive breast cancer, regardless of whether it was a prospective cohort or one formed retrospectively were identified. Only articles were examined that reported a cohort of patients with SLNB-positive breast carcinoma confirmed by SLNB and had follow-up data. The status of the positive SLNB was classified into three categories: micrometastatic lymph node $(\leq 2.0 \mathrm{~mm})$, macrometastatic lymph node $(>2.0 \mathrm{~mm})$ and not specified. Distinction between isolated tumor cells (ITC; $<0.02 \mathrm{~mm}$ ) and micrometastatic disease $(0.02-2.0 \mathrm{~mm})$ was not presented in all articles and these were therefore combined as micrometastatic $(\leq 2.0 \mathrm{~mm})$. Only SLNB-positive patients without a cALND were included. Cases in which it was uncertain whether cALND had been performed were excluded. Failure to report on the ARR also resulted in exclusion from this review.

Adjuvant treatment (radiation, chemotherapy or hormone therapy) was not subject to review. Therefore, failure to report on the percentage of patients receiving adjuvant treatment did not result in exclusion from this study. An effort was made, however, to extract data on adjuvant treatment when documented. Two studies reported $100 \%$ of the observed patients had received axillary radiotherapy and were excluded. Additional information on age, clinical $\mathrm{T}$ stage, lymphovascular invasion and type of surgery was also collected.

Each article was reviewed independently by the two reviewers (C.F. and P.D.), and discrepancies were resolved by consensus.

\section{Identification of Axillary Recurrence}

Axillary recurrence was defined as the detection of metastatic disease in the axilla based on a positive SLNB. Patients with concurrent breast relapse who had developed axillary disease based on a positive SLNB were not considered as having an axillary recurrence. In these instances, the axillary recurrence could reflect insufficient local control of the primary tumor. Additionally, some articles only mentioned local or locoregional recurrence. The latter were classified as having an axillary recurrence.

\section{Statistical Analysis}

Patient and tumor related characteristics and ARRs were calculated by descriptive statistics.

\section{RESULTS}

A total of 216 articles were found in the PubMed database; after an intensive review of the analysis reported in the abstract, only 35 remained. The two articles reporting axillary radiotherapy in $100 \%$ of the patients were excluded. ${ }^{17,18}$ Three research groups reported results from the same cohort in two or three different articles with a progressively longer follow-up or an increased group size. The articles with data reporting the longest follow-up were included. $^{19-21}$ Therefore, 30 articles were eligible for analysis in this review. $9,10,14-16,19-43$ 


\section{Description of Study Data}

In 30 articles results were presented for a total of 7,151 patients with SLNB-positive breast cancer in which a cALND had not been performed. Median follow-up was 45 months (range 1-142 months). One study reported an underpowered multicenter randomized clinical trial. ${ }^{9}$ Two studies reported results from a nationwide database. ${ }^{10,22}$ All the other series were single center reports. ${ }^{9,10,14-16,19-43}$

A cALND was not performed because of patient or clinician preference. ${ }^{14-16,21,24,35,37-40,42}$ Some studies retrospectively analyzed patients with postoperative confirmed positive SLNs, in which no secondary surgery had been performed on the axilla. ${ }^{19,25,27,36,41,43}$ In total, 41 patients developed an axillary recurrence without evidence of ipsilateral breast cancer recurrence. The ARR varied between 0 and $7.1 \%$ in the different studies.

\section{ARR After Micrometastases/ITCs are Found in the Sentinel Node}

We further classified patients on the basis of the sentinel node status. In a total of 27 studies 3,468 patients were identified with micrometastatic disease in the sentinel node who had not undergone a cALND (Table 1). Median follow-up was 42 months; 10 patients $(0.3 \%)$ developed an axillary recurrence. The axillary recurrences were reported to occur in 3 patients who underwent breast-conserving therapy (BCT) and in 2 patients who underwent mastectomy. In 5 patients an axillary recurrence was reported, but details regarding the type of breast surgery was not mentioned in the article. Of the 10 patients, two were treated with adjuvant radiotherapy and one without. In the other patients, only percentages of radiotherapy in the total group of patients were given ( $21 \%$ up to $72 \%$ ) or radiotherapy was not mentioned at all. ${ }^{9,10,22-24,33,35}$

Two of the 27 studies investigated national databases. From the Surveillance, Epidemiology, and End Results database, Yi et al. ${ }^{22}$ identified 26,986 patients with diseasepositive lymph nodes, of which 4,425 (16.4\%) had only undergone SLNB. After nodal evaluation with lymph node count threshold, i.e. patients were considered only to have undergone a SLNB if they had had five or fewer nodes examined, 3,240 patients remained with a median age of 60 years (range 24-96 years). Of these patients, 1767 had micrometastatic disease in the SLN and an ipsilateral regional event was seen in $0.1 \%$.

Bilimoria et al. ${ }^{10}$ identified 97,314 patients in the United States National Cancer Data Base with clinically nodenegative breast cancer who had had a positive sentinel node. Of these, $20.8 \%$ had undergone a SLNB without a cALND. Only patients diagnosed between 1998-2000 with a follow-up reported between 2004 and 2006 were used in the outcome analysis; 1,988 (9.8\%) had only undergone SLNB. The median age was 58 years (range 49-69 years), median follow-up was 64 months. Axillary recurrences were seen in $0.6 \%$ of the 530 patients with microscopic nodal metastases.

The 25 other studies reported on smaller cohorts in which the ARR varied between 0 and $3.7 \%$. The median age was 58 years (range 53-67 years), most patients had undergone BCT (44-100\%) and had received some form of adjuvant systemic therapy (36-100\%). Nine studies reported on radiotherapy of the axilla in $2-63 \%$ of patients. ${ }^{14,16,19,25-27,29,35,39}$

\section{ARR After Macrometastases are Found in the Sentinel Node}

Table 2 shows 16 studies that described patients with macrometastatic disease in the SLN in whom a cALND had not been performed. A total of 3,268 patients were identified, with a median follow-up of 43 months (range 1-142 months). Twenty-four axillary recurrences were observed $(0.7 \%)$. In this group the median age was 58 years (range 53-64 years). The national database study by Yi et al. ${ }^{22}$ showed an ARR of $0.1 \%$ in 1,473 patients with macrometastatic disease; Bilimoria et al. ${ }^{10}$ found an ARR of $1.2 \%$. The studies that reported on smaller cohorts showed an ARR between 0 and $7.1 \%$. The latter was observed in a study with only 14 patients. In case of macrometastatic disease in the sentinel node, 6 studies reported that patients had been treated with axillary radiotherapy in $2-63 \%$ of the patients. ${ }^{14,16,19,29,35,40}$ In the majority of patients who developed an axillary recurrence $(n=24)$ details regarding the type of surgery of the primary tumor were lacking. Three of the patients in this group were treated with BCT. Detailed information regarding adjuvant radiotherapy was also lacking. Of the 24 patients with an axillary recurrence, 3 patients received radiotherapy. In the other patients, only percentages of radiotherapy in the total group of patients were given (21\% up to $72 \%) .{ }^{9,10,22,24}$

Table 3 shows four studies that reported SLNB positivity, but which did not describe the exact sentinel node status. A total of 409 patients with a median follow-up of 55 months were identified. The ARR varied between 0 and $2.1 \%$, and a total of 7 axillary recurrences had been noted. One study included patients receiving axillary radiotherapy; however, this applied to only $15 \%$ of the patients. ${ }^{21}$

\section{DISCUSSION}

Recent studies have questioned the need for a cALND in patients with a positive SLNB because the ARR is 


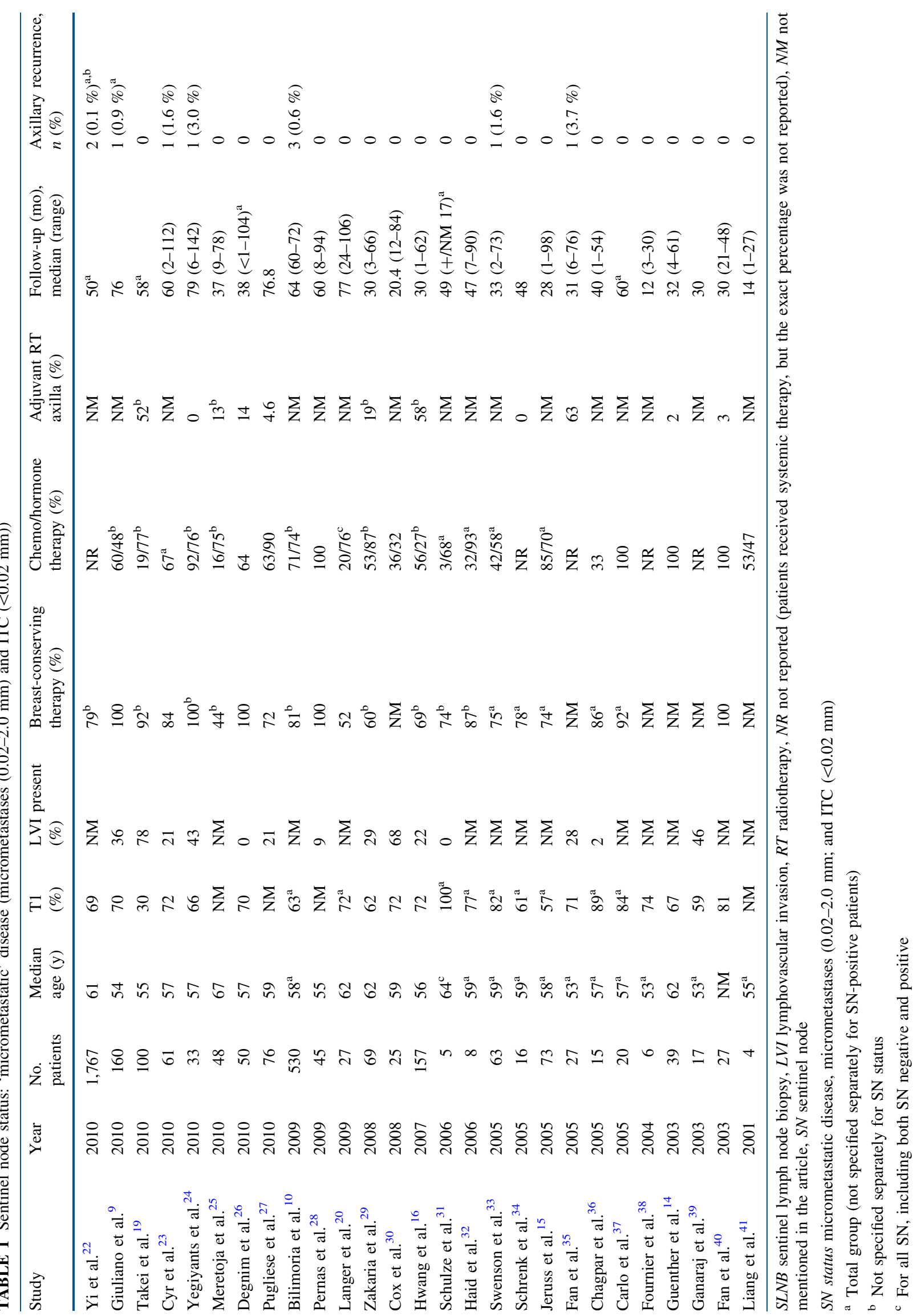


TABLE 2 Sentinel node status: macrometastatic disease $(>2.0 \mathrm{~mm})$

\begin{tabular}{|c|c|c|c|c|c|c|c|c|c|c|}
\hline Source & Year & $\begin{array}{l}\text { No. } \\
\text { patients }\end{array}$ & $\begin{array}{l}\text { Median } \\
\text { age }(y)\end{array}$ & $\begin{array}{l}\mathrm{T} 1 \\
(\%)\end{array}$ & $\begin{array}{l}\text { LVI } \\
\text { present } \\
(\%)\end{array}$ & $\begin{array}{l}\text { Breast- } \\
\text { conserving } \\
\text { therapy }(\%)\end{array}$ & $\begin{array}{l}\text { Chemo/ } \\
\text { hormone } \\
\text { therapy }(\%)\end{array}$ & $\begin{array}{l}\text { Adjuvant } \\
\text { RT axilla } \\
(\%)\end{array}$ & $\begin{array}{l}\text { Follow-up (mo), } \\
\text { median (range) }\end{array}$ & $\begin{array}{l}\text { Axillary } \\
\text { recurrence, } \\
n(\%)\end{array}$ \\
\hline Yi et al. ${ }^{22}$ & 2010 & 1,473 & 61 & 69 & $\mathrm{NM}$ & $79^{\mathrm{b}}$ & NR & NM & $50^{\mathrm{a}}$ & $3(0.2 \%)$ \\
\hline Giuliano et al. $^{9}$ & 2010 & 199 & 54 & 70 & 36 & 100 & $60 / 48^{\mathrm{b}}$ & $\mathrm{NM}$ & 76 & $2(0.9 \%)^{\mathrm{b}}$ \\
\hline Takei et al. ${ }^{19}$ & 2010 & 32 & 55 & 30 & 78 & $92^{\mathrm{b}}$ & $19 / 77^{\mathrm{b}}$ & $52^{\mathrm{b}}$ & $58^{\mathrm{a}}$ & 0 \\
\hline Yegiyants et al. ${ }^{24}$ & 2010 & 14 & 57 & 66 & 43 & 100 & $92 / 76^{\mathrm{b}}$ & 0 & $79(6-142)$ & $1(7.1 \%)$ \\
\hline Bilimoria et al. ${ }^{10}$ & 2009 & 1,458 & $58^{\mathrm{a}}$ & $63^{\mathrm{a}}$ & $\mathrm{NM}$ & $81^{\mathrm{b}}$ & $71 / 74^{\mathrm{b}}$ & $\mathrm{NM}$ & $64(60-72)$ & $18(1.2 \%)$ \\
\hline Zakaria et al. $^{29}$ & 2008 & 17 & 62 & 62 & 29 & $60^{\mathrm{b}}$ & $53 / 87^{\mathrm{b}}$ & $19^{\mathrm{b}}$ & $30(3-66)$ & 0 \\
\hline Hwang et al. ${ }^{16}$ & 2007 & 39 & 56 & 72 & 22 & $69^{\mathrm{b}}$ & $56 / 27^{\mathrm{b}}$ & $58^{\mathrm{b}}$ & $30(1-62)$ & 0 \\
\hline Schulze et al. ${ }^{31}$ & 2006 & 1 & $64^{\mathrm{c}}$ & $100^{\mathrm{a}}$ & 0 & $74^{\mathrm{b}}$ & $3 / 68^{a}$ & NM & $49(+/ \mathrm{NM} 17)^{\mathrm{a}}$ & 0 \\
\hline Haid et al. ${ }^{32}$ & 2006 & 2 & $59^{\mathrm{a}}$ & $77^{\mathrm{a}}$ & $\mathrm{NM}$ & $87^{\mathrm{b}}$ & $32 / 93^{\mathrm{a}}$ & NM & $47(7-90)$ & 0 \\
\hline Swenson et al. ${ }^{33}$ & 2005 & 4 & $59^{\mathrm{a}}$ & $82^{\mathrm{a}}$ & NM & $75^{\mathrm{b}}$ & $42 / 58^{\mathrm{a}}$ & NM & $33(2-73)$ & 0 \\
\hline Schrenk et al. ${ }^{34}$ & 2005 & 4 & $59^{\mathrm{a}}$ & $61^{\mathrm{a}}$ & $\mathrm{NM}$ & $29^{\mathrm{b}}$ & NR & 0 & 48 & 0 \\
\hline Fan et al. ${ }^{35}$ & 2005 & 11 & $53^{\mathrm{a}}$ & 71 & 28 & $\mathrm{NM}$ & NR & $63^{\mathrm{b}}$ & $31(6-76)$ & 0 \\
\hline Chagpar et al. ${ }^{36}$ & 2005 & 1 & $57^{\mathrm{a}}$ & $89^{\mathrm{a}}$ & 2 & $86^{\mathrm{b}}$ & $33^{\mathrm{b}}$ & NM & $40(1-54)$ & 0 \\
\hline Carlo et al. ${ }^{37}$ & 2005 & 2 & $57^{\mathrm{a}}$ & $84^{\mathrm{a}}$ & $\mathrm{NM}$ & $92^{\mathrm{a}}$ & 100 & $\mathrm{NM}$ & $60^{\mathrm{a}}$ & 0 \\
\hline Guenther et al. ${ }^{14}$ & 2003 & 7 & 62 & 67 & $\mathrm{NM}$ & $\mathrm{NM}$ & 100 & $2^{\mathrm{b}}$ & $32(4-61)$ & 0 \\
\hline Fant et al. ${ }^{40}$ & 2003 & 4 & NM & 81 & NM & NM & 100 & $3^{\mathrm{b}}$ & $30(21-48)$ & 0 \\
\hline
\end{tabular}

$S L N B$ sentinel lymph node biopsy, LVI lymphovascular invasion, $R T$ radiotherapy, $N R$ not reported (patients received systemic therapy, but the exact percentage was not reported), $N M$ not mentioned in the article, $S N$ sentinel node

SN status macrometastatic disease $(>2.0 \mathrm{~mm})$

a Total group (not specified separately for SN-positive patients)

b Not specified separately for SN status

${ }^{c}$ For all SN, including both SN negative and positive

TABLE 3 Sentinel node status: not specified

\begin{tabular}{|c|c|c|c|c|c|c|c|c|c|c|}
\hline Source & Year & $\begin{array}{l}\text { No. } \\
\text { patients }\end{array}$ & $\begin{array}{l}\text { Median } \\
\text { age }(y)\end{array}$ & $\begin{array}{l}\mathrm{T} 1 \\
(\%)\end{array}$ & $\begin{array}{l}\text { LVI } \\
\text { present } \\
(\%)\end{array}$ & $\begin{array}{l}\text { Breast- } \\
\text { conserving } \\
\text { therapy }(\%)\end{array}$ & $\begin{array}{l}\text { Chemo/ } \\
\text { hormone } \\
\text { therapy }(\%)\end{array}$ & $\begin{array}{l}\text { Adjuvant } \\
\text { RT axilla } \\
(\%)\end{array}$ & $\begin{array}{l}\text { Follow-up (mo), } \\
\text { median (range) }\end{array}$ & $\begin{array}{l}\text { Axillary } \\
\text { recurrence, } \\
n(\%)\end{array}$ \\
\hline Giuliano et al. $^{9}$ & 2010 & 66 & $54^{\mathrm{b}}$ & 70 & 36 & 100 & $60 / 48^{\mathrm{b}}$ & NM & 76 & $1(0.9 \%)^{\mathrm{b}}$ \\
\hline Geertsema et al. ${ }^{43}$ & 2010 & 39 & $60^{\mathrm{a}}$ & $64^{a}$ & NM & NM & $\mathrm{NM}$ & NM & $40^{\mathrm{b}}$ & 0 \\
\hline Park et al. ${ }^{21}$ & 2007 & 287 & 59 & 78 & 22 & 68 & NR & 15 & $23(6-87)$ & $6(2.1 \%)$ \\
\hline Calhoun et al. ${ }^{42}$ & 2005 & 17 & 64 & 65 & NM & NM & 88 & NM & $81^{\mathrm{a}}$ & 0 \\
\hline
\end{tabular}

$S L N B$ sentinel lymph node biopsy, $L V I$ lymphovascular invasion, $R T$ radiotherapy, $N R$ not reported (patients received systemic therapy, but the exact percentage was not reported), $N M$ not mentioned in the article, $S N$ sentinel node

SN status not specified

a Total group (not specified separately for SN-positive patients)

b Not specified separately for SN status

relatively low if cALND has not been performed. In daily practice, a shift toward omitting the cALND in these patients is taking place, especially in those patients with micrometastatic disease. Results from two large database studies in the US demonstrate that already $16.4-20.8 \%$ of the patients with a positive sentinel node did not undergo axillary treatment. ${ }^{10,22}$ The present review demonstrates low ARRs in studies which included at least 100 patients for patients who did not undergo a cALND although they had a tumor-positive SLNB. ${ }^{9,10,16,18,22}$ The rates varied between 0 and $0.9 \%$ for micrometastatic disease and 0.2 to $1.2 \%$ for macrometastatic disease. These rates are comparable to those seen in patients with a positive SLNB in which a cALND had been performed (recurrence rates between 0.2 and $1.0 \%) .{ }^{9,10}$ The rates found are also of the same magnitude as those for patients with a negative SLNB 
(without cALND) for whom the ARR ranged from 0.3 to $1.4 \% .^{11,44}$

In this review we included the preliminary results from the ACOSOG Z0011 trial. This is the only prospective trial in which patients with sentinel node metastases were randomized to undergo axillary lymph node dissection after SLNB versus SLNB without specific axillary treatment. ${ }^{9}$ All these patients were treated with BCT and tangential field whole breast irradiation. In addition, the majority of the patients $(97 \%)$ in that study received adjuvant systemic treatment. At a median follow-up of 6.3 years (interquartile range 5.2-7.7), no significant difference was seen in the ARR between the two groups $(0.5 \%$ in the cALND group and $0.9 \%$ in the group without cALND). Moreover, overall survival was not different in both study arms. $^{45}$ Unfortunately, the trial was underpowered and closed early because accrual was low and the ARR was lower than expected in both arms., 9,45

In addition to the low chance of recurrence shown by the ARR, there are other arguments to eliminate a cALND for selected patients. First of all, in the current guidelines adjuvant systemic therapy is advised on the basis of tumor and patient characteristics and axillary lymph node involvement. Treatment recommendations are rarely altered by the additional information gained by the cALND results. Geertsema et al. $^{43}$ reported additional tumor positive axillary lymph nodes in $16 \%$ of the patients undergoing a cALND after a negative frozen section. None of those patients would have received additional systemic therapy on the basis of the cALND findings. The AMAROS trial compared cALND with axillary radiotherapy in positive sentinel node patients. It also demonstrated that information obtained from cALND rarely altered treatment recommendations made before the cALND. ${ }^{4,6}$ Although patients with four or more positive lymph nodes are supposed to receive adjuvant radiotherapy on the axilla and supraclavicular region, that was only necessary in $12 \%$ of the patients in the trial. ${ }^{6,46}$ Most probably the majority of patients with four or more positive lymph nodes were preoperatively identified by palpation or ultrasound as being node positive and did not undergo SLNB as such patients routinely undergo an axillary dissection at the same time as treatment for the primary tumor.

Secondly, only in 10-20\% of patients with ITCs and micrometastases and around $40 \%$ of patients with macrometastases does the cALND contains additional lymph node metastases. ${ }^{6,47}$ Several nomograms have been developed to predict the chance of additional lymph node metastases; however, each has limitations. ${ }^{48,49}$ Because in the general population the majority of additional lymph nodes are negative, performing a cALND would have no therapeutic value or additional staging effects.

Thirdly, the effect of additional systemic therapy in patients with node positive disease is an important issue. A few decades ago Canabes et al. ${ }^{50}$ had reported that the ARR in patients with tumors smaller than $3 \mathrm{~cm}$ was only $2 \%$ if the axilla had not been treated. That study compared axillary dissection to no axillary dissection. However, that occurred in an era in which only a minority of the patients were treated with adjuvant systemic therapy. Now that modern systemic therapy is given in almost all patients with a positive SLNB, the recurrence rate now that can be expected will most probably be lower. The MIRROR trial studied the effects of systemic therapy in patients with ITCs or micrometastases regardless of axillary treatment; it demonstrated an improvement of disease-free survival in patients who had received adjuvant systemic therapy. ${ }^{51}$ In neo-adjuvant chemotherapy protocols, not only is the size of the tumor substantially reduced but also the size of lymph node metastases. ${ }^{52}$ Pathological complete response by the primary tumor has been demonstrated to be highly predictive of pathological complete response in the axillary nodes. ${ }^{53}$ Charfare et al. ${ }^{54}$, Vlastos et al. ${ }^{55}$ and Kuerer et al. $^{56}$ reported a pathologically complete response in 3-34\% of the patients. Thus, patients with a positive lymph node status at initial evaluation, can be considered to have a negative axillary nodal status as a result of neoadjuvant chemotherapy. ${ }^{54-56}$ This effect might also be of importance in adjuvant chemotherapy protocols. Therefore, potentially positive lymph nodes in the axilla could be sterilized by chemotherapy, which would then reduce the theoretical ARR.

Fourthly, not only systemic therapy but also adjuvant radiotherapy can be regarded as a treatment modality for any remaining axillary lymph node metastases. Radiotherapy to the breast as part of BCT includes the lowest portion of the axilla. In several studies it has been objectified that the clip marking the SLN fell within the standard tangential fields of the whole breast radiotherapy in $78-94 \%$ of the patients. ${ }^{57,58}$ Veronesi et al. ${ }^{59}$ described that radiotherapy to the breast is one of the possible explanations for the lower than expected numbers of axillary metastases in the no axillary radiotherapy arm of their randomized trial to assess the role of axillary radiotherapy. A recently published systematic review demonstrated that patients with a node negative SLN who underwent radiotherapy had a significantly lower rate of axillary recurrences as compared to patients who had not been not treated with postoperative radiotherapy of the breast. ${ }^{60}$

A limitation of this review is the fact that all but one of the reviewed studies were retrospectively analyzed. It is therefore difficult to control for treatment bias and selection bias. In some studies patients were more likely to be older and have more favorable tumors characteristics such as smaller size, low tumor grade and less lymphovascular infiltration than in the general breast cancer population. This is shown in Table 4 by the trend for smaller tumor 
TABLE 4 Patients, tumor and treatment characteristics in studies with $>100$ patients who underwent SLNB only for positive breast cancer, compared with patients who underwent ALND

\begin{tabular}{|c|c|c|c|}
\hline Favorable characteristic & Study $^{\mathrm{a}}$ & ALND & SLNB only \\
\hline \multirow{6}{*}{ Tumor size $<2 \mathrm{~cm}(\%)$} & Yi et al. & 50.4 & 68.6 \\
\hline & Giuliano et al. & 67.9 & 70.6 \\
\hline & Takei et al. & $\mathrm{x}$ & 29.5 \\
\hline & Bilimoria et al. & 49.1 & 62.9 \\
\hline & Hwang et al. & $\mathrm{x}$ & 72.4 \\
\hline & Park et al. & 62 & 78 \\
\hline \multirow[t]{6}{*}{ Radiotherapy (\%) } & Yi et al. & 53.6 & 59.9 \\
\hline & Giuliano et al. & $\mathrm{NM}$ & NM \\
\hline & Takei et al. & $\mathrm{x}$ & 84.8 \\
\hline & Bilimoria et al. & $72.1^{\mathrm{b}}$ & $72.1^{\mathrm{b}}$ \\
\hline & Hwang et al. & $\mathrm{x}$ & 58.2 \\
\hline & Park et al. & $\mathrm{NM}$ & 15 \\
\hline \multirow[t]{6}{*}{ Median age (y) } & Yi et al. & 55 & 60 \\
\hline & Giuliano et al. & 56 & 54 \\
\hline & Takei et al. & $\mathrm{x}$ & 55 \\
\hline & Bilimoria et al. & 56 & 58 \\
\hline & Hwang et al. & $\mathrm{x}$ & 56 \\
\hline & Park et al. & 52 & 59 \\
\hline \multirow[t]{6}{*}{ Breast-conserving surgery $(\%)$} & Yi et al. & 53.9 & 78.7 \\
\hline & Giuliano et al. & 100 & 100 \\
\hline & Takei et al. & $\mathrm{x}$ & 92.4 \\
\hline & Bilimoria et al. & 49.6 & 81.4 \\
\hline & Hwang et al. & $\mathrm{x}$ & 68.9 \\
\hline & Park et al. & 55 & 68 \\
\hline \multirow[t]{6}{*}{ Micrometastases (\%) } & Yi et al. & 17.2 & 54.5 \\
\hline & Giuliano et al. & 37.5 & 44.8 \\
\hline & Takei et al. & $\mathrm{x}$ & 56.8 \\
\hline & Bilimoria et al. & 8.5 & 18.2 \\
\hline & Hwang et al. & $\mathrm{x}$ & 45.9 \\
\hline & Park et al. & $\mathrm{NM}$ & $\mathrm{NM}$ \\
\hline \multirow[t]{6}{*}{ No. of LNs removed, median (range) } & Yi et al. & $15(9-64)$ & $2(1-5)$ \\
\hline & Giuliano et al. & 17 & 2 \\
\hline & Takei et al. & $\mathrm{x}$ & $3(1-11)$ \\
\hline & Bilimoria et al. & $15(12-20)$ & $2(1-3)$ \\
\hline & Hwang et al. & $\mathrm{x}$ & $3(1-14)$ \\
\hline & Park et al. & $>10$ & NM (1-9) \\
\hline
\end{tabular}

SLNB sentinel lymph node biopsy, $A L N D$ axillary lymph node dissection, $L N$ lymph node, $N M$ not mentioned in the article, $S N$ sentinel node, $x=$ no comparison with a group patients treated with ALND is made

${ }^{\text {a }}$ Studies are as follows: Yi et al. ${ }^{22}$, Giuliano et al. ${ }^{9}$, Takei et al. ${ }^{19}$ (total group, not specified separately for $\mathrm{SN}$ positive patients), Bilimoria et al. ${ }^{10}$, Hwang et al. ${ }^{16}$ (total group, not specified separately for SN-positive patients), and Park et al. ${ }^{21}$ (in ALND

$95.7 \%>10$ nodes excised, in SLNB $85 \%$ 1-9 nodes excised)

b After breast-conserving surgery
SLNB if they were more likely to have a favorable prognosis. Also, these cancer registries may underreport axillary recurrences because the definition "ipsilateral regional events" is used instead of "axillary recurrence." Although the other studies do use the exact definition, underreporting might still occur in all studies because of their retrospective nature.

The mean follow-up in the studies in this review ranged between 1 and 142 months, which is relatively short for drawing definite conclusions about axillary recurrence. However, studies with long-term follow-up have shown that the majority of locoregional recurrences, including 
axillary relapses, occur within five years of the initial treatment and most axillary recurrences (approximately $90 \%$ ) are evident within the first 2 or 3 years after surgery. This compares well to the median follow-up for the present study ${ }^{61,62}$

Heterogeneity among the included studies was substantial and is a major drawback of this review. Although BCT was performed in the majority of patients for all reviewed studies, the results in each individual study were not given separately for BCT versus mastectomy. With regard to adjuvant treatment, most of the studies reported that adjuvant treatment was given according to the national guidelines, but the adjuvant treatment was not specified for those patients with a recurrence. Radiotherapy on the axilla was also given in 10 of these studies but a substantial number of patients in each study did not receive that therapy. This is an important issue because the MA.20 preliminary report demonstrated a reduction in locoregional recurrence when the axilla has been irradiated. ${ }^{63}$ This makes it difficult to form definite conclusions about the influence of adjuvant systemic therapy and radiotherapy on the recurrence rate. The absence of the distinction between micrometastases and ITCs in some of the studies is also a drawback because patients with ITCs in the SLNB are nowadays classified as "node-negative patients," not requiring a cALND. Recently Jakub et al. ${ }^{64}$ suggested that not the number of positive SLN, but the number of positive non-SLNs is important for prognosis. Details about this issue of additional non-SLN positivity are lacking in the reviewed studies.

Lastly, the definition and surgical technique of the SLNB itself is a limitation. In daily routine most patients have one or two SLNs, but in the six studies with 100 or more patients in this review mean number of biopsied nodes is $2-11$ nodes. In the two large American databases, before analysis with lymph node count threshold (five or fewer nodes examined) 4-16 nodes and 1-44 nodes were included as SLNB patients, which should probably be considered as complete axillary lymph node dissections.

Overall survival was not subject of this review, although it is clinically relevant to investigate whether omission of cALND affects survival. Yi et al. ${ }^{22}$ stated that compared with SLNB alone, cALND does not seem to be associated with improved survival in patients with micrometastasis in the SLNB. Bilimoria et al. ${ }^{10}$ described that, in case of micrometastases, a cALND does not appear to improve the overall outcome, as there were no significant differences in survival or in axillary recurrences. In case of macrometastatic disease, there was a nonsignificant trend toward better outcomes in axillary recurrences and survival after cALND, but only after analysis was adjusted for clinicopathologic differences. ${ }^{10}$ In the ACOSOG Z0011 trial, Giuliano et al. ${ }^{65}$ observed no differences in overall survival between the cALND arm and the arm in which cALND was not performed. Long-term results and the impact of the omission of axillary lymph node dissection on survival are awaited.

In conclusion, this review shows that the ARR is low in patients with a positive SLNB, even if a cALND is not performed. Recent efforts to develop nomograms in order to predict which patients should undergo a cALND, fails to identify patients who really benefit of this procedure. On the contrary, avoiding a cALND seems to be safe in the majority of SLNB-positive patients, especially in case of ITCs or micrometastatic disease. In patients who meet the Z0011 trial criteria and undergo adjuvant radiotherapy and chemotherapy, cALND has little to no effect on local recurrence and survival. However, large (prospective randomized) studies are lacking for patients with a potentially higher risk for regional recurrences such as multiple macrometastases in the SLN, patients with larger primaries, patients who underwent neoadjuvant chemotherapy or patients undergoing mastectomy or BCT without radiotherapy. Such randomized trials or large clinical cohort studies are necessary to investigate the long-term effects on axillary recurrences and survival of omitting cALND in high risk patients. ${ }^{66,67}$ In the future, cALND will probably be used as an effective treatment procedure rather than a procedure to prevent axillary recurrence. ${ }^{68}$

OPEN ACCESS This article is distributed under the terms of the Creative Commons Attribution License which permits any use, distribution, and reproduction in any medium, provided the original author(s) and the source are credited.

\section{REFERENCES}

1. Giuliano AE, Kirgan DM, Guenther JM, et al. Lymphatic mapping and sentinel lymphadenectomy for breast cancer. Ann Surg. 1994;220:391-98.

2. Veronesi U, Paganelli G, Viale G, et al. Sentinel-lymph-node biopsy as a staging procedure in breast cancer: update of a randomised controlled study. Lancet Oncol. 2006;7:983-90.

3. Lyman GH, Giuliano AE, Somerfield MR, et al. American Society of Clinical Oncology guideline recommendations for sentinel lymph node biopsy in early-stage breast cancer. J Clin Oncol. 2005;23:7703-20.

4. Straver ME, Meijnen P, van Tienhoven G, et al. Role of axillary clearance after a tumor-positive sentinel node in the administration of adjuvant therapy in early breast cancer. J Clin Oncol. 2010;28:731-7.

5. Hurkmans CW, Borger JH, Rutgers EJ. Quality assurance of axillary radiotherapy in the EORTC AMAROS trial 10981/22023: the dummy run. Radiother Oncol. 2003;68:233-40.

6. Straver ME, Meijnen P, van Tienhoven G, et al. Sentinel node identification rate and nodal involvement in the EORTC 10981-22023 AMAROS trial. Ann Surg Oncol. 2010;17:1854-61.

7. Del Bianco P, Zavagno G, Burelli P, et al. Morbidity comparison of sentinel lymph node biopsy versus conventional axillary lymph node dissection for breast cancer patients: results of the 
Sentinella-GIVOM Italian randomised clinical trial. Eur J Surg Oncol. 2008;34:508-13.

8. Yeoh EK, Denham JW, Davies SA, et al. Primary breast cancer: complications of axillary management. Acta Radiol Oncol. 1986;25:105-108.

9. Giuliano AE, McCall L, Beitsch P, et al. Locoregional recurrence after sentinel lymph node dissection with or without axillary dissection in patients with sentinel lymph node metastases. Ann Surg. 2010;252:426-32.

10. Bilimoria KY, Bentrem DJ, Hansen NM, et al. Comparison of sentinel lymph node biopsy alone and completion axillary lymph node dissection for node-positive breast cancer. J Clin Oncol. 2009;27:2946-53.

11. Naik AM, Fey J, Gemignani M, et al. The risk of axillary relapse after sentinel lymph node biopsy for breast cancer is comparable with that of axillary lymph node dissection: a follow-up study of 4008 procedures. Ann Surg. 2004;240:462-8.

12. Fisher B, Jeong JH, Anderson S, et al. Twenty-five-year followup of a randomized trial comparing radical mastectomy, total mastectomy, and total mastectomy followed by irradiation. $N$ Engl J Med. 2002;347:567-75.

13. Lucci A, McCall LM, Beitsch PD, et al. Surgical complications associated with sentinel lymph node dissection (SLND) plus axillary lymph node dissection compared with SLND alone in the American College of Surgeons Oncology Group Trial Z0011. J Clin Oncol. 2007;25:3657-63.

14. Guenther JM, Hansen NM, DiFronzo LA, et al. Axillary dissection is not required for all patients with breast cancer and positive sentinel nodes. Arch Surg. 2003;138:52-6.

15. Jeruss JS, Winchester DJ, Sener SF, et al. Axillary recurrence after sentinel node biopsy. Ann Surg Oncol. 2005;12:34-40.

16. Hwang RF, Gonzalez-Angulo A, Yi M, et al. Low locoregional failure rates in selected breast cancer patients with tumor-positive sentinel lymph nodes who do not undergo completion axillary dissection. Cancer. 2007;110:723-30.

17. Van der Vegt B, Doting MH, Jager PH, et al. Axillary recurrence after sentinel lymph node biopsy. Eur J Surg Oncol. 2004,30: 715-20.

18. Pejavar S, Wilson LD, Haffty BG. Regional nodal recurrence in breast cancer patients treated with conservative surgery and radiation therapy (BCS + RT). Int J Radiat Oncol Biol Phys. 2006;66:1320-7.

19. Takei H, Kurosumi M, Yoshida T, et al. Axillary lymph node dissection can be avoided in women with breast cancer with intraoperative, false-negative sentinel lymph node biopsies. Breast Cancer. 2010;17:9-16.

20. Langer I, Guller U, Viehl CT, et al. Axillary lymph node dissection for sentinel lymph node micrometastases may be safely omitted in early-stage breast cancer patients: long-term outcomes of a prospective study. Ann Surg Oncol. 2009;16:3366-74.

21. Park J, Fey JV, Naik AM, et al. A declining rate of completion axillary dissection in sentinel lymph node-positive breast cancer patients is associated with the use of a multivariate nomogram. Ann Surg. 2007;245:462-8.

22. Yi M, Giordano SH, Meric-Bernstam F, et al. Trends in and outcomes from sentinel lymph node biopsy (SLNB) alone vs. SLNB with axillary lymph node dissection for node-positive breast cancer patients: experience from the SEER database. Ann Surg Oncol. 2010;17:S343-51.

23. Cyr A, Gillanders WE, Aft RL, et al. Micrometastatic disease and isolated tumor cells as a predictor for additional breast cancer axillary metastatic burden. Ann Surg Oncol. 2010;17:S303-11.

24. Yegiyants S, Romero LM, Haigh PI, et al. Completion axillary lymph node dissection not required for regional control in patients with breast cancer who have micrometastases in a sentinel node. Arch Surg. 2010;145:564-9.
25. Meretoja TJ, Vironen JH, Heikkilä PS, et al. Outcome of selected breast cancer patients with micrometastasis or isolated tumor cells in sentinel node biopsy and no completion axillary lymph node dissection. J Surg Oncol. 2010;102:215-9.

26. Degnim AC, Zakaria S, Bouhey JC, et al. Axillary recurrence in breast cancer patients with isolated tumor cells in the sentinel lymph node [AJCC NO(i+)]. Ann Surg Oncol. 2010;17:2685-9.

27. Pugliese MS, Karam AK, Hsu M, et al. Predictors of completion axillary lymph node dissection in patients with immunohistochemical metastases to the sentinel lymph node in breast cancer. Ann Surg Oncol. 2010;17:1063-68.

28. Pernas S, Gil M, Benítez A, et al. Avoiding axillary treatment in sentinel lymph node micrometastases of breast cancer: a prospective analysis of axillary or distant recurrence. Ann Surg Oncol. 2010;17:772-7.

29. Zakaria S, Pantvaidya G, Reynolds CA, et al. Sentinel node positive breast cancer patients who do not undergo axillary dissection: are they different? Surgery. 2008;143:641-7.

30. Cox CE, Kiluk JV, Riker AI, et al. Significance of sentinel lymph node micrometastase in human breast cancer. J Am Coll Surg. 2008;206:261-8.

31. Schulze T, Mucke J, Markwardt J, et al. Long-term morbidity of patients with early breast cancer after sentinel lymph node biopsy compared to axillary lymph node dissection. J Surg Oncol. 2006;93:109-19.

32. Haid A, Knauer M, Köberle-Wührer R, et al. Medium-term follow-up data after sentinel node biopsy alone for breast cancer. Eur J Surg Oncol. 2006;32:1180-5.

33. Swenson KK, Mahipal A, Nissen MJ, et al. Axillary disease recurrence after sentinel lymph node dissection for breast carcinoma. Cancer. 2005;104:1834-9.

34. Schrenk P, Konstantiniuk P, Wölfl S, et al. Prediction of nonsentinel lymph node status in breast cancer with a micrometastatic sentinel node. Br J Surg. 2005;92:707-13.

35. Fan YG, Tan YY, Wu CT, et al. The effect of sentinel node tumor burden on non-sentinel node status and recurrence rates in breast cancer. Ann Surg Oncol. 2005;12:705-11.

36. Chagpar A, Middleton LP, Sahin AA, et al. Clinical outcome of patients with lymph node-negative breast carcinoma who have sentinel lymph node micrometastases detected by immunohistochemistry. Cancer. 2005;103:1581-6.

37. Carlo JT, Grant MD, Knox SM, et al. Survival analysis following sentinel lymph node biopsy: a validation trial demonstrating its accuracy in staging early breast cancer. Proc (Bayl Univ Med Cent). 2005;18:103-7.

38. Fournier K, Schiller A, Perry RR, et al. Micrometastasis in the sentinel lymph node of breast cancer does not mandate completion axillary dissection. Ann Surg. 2004;239:859-63.

39. Ganaraj A, Kuhn JA, Jones RC. Predictors for nonsentinel node involvement in breast cancer patients with micrometastases in the sentinel lymph node. Proc (Bayl Univ Med Cent). 2003;16:3-6.

40. Fant JS, Grant MD, Knox SM, et al. Preliminary outcome analysis in patients with breast cancer and a positive sentinel lymph node who declined axillary dissection. Ann Surg Oncol. 2003;10:126-30.

41. Liang WC, Sickle-Santanello BJ, Nims TA. Is a completion axillary dissection indicated for micrometastases in the sentinel lymph node? Am J Surg. 2001;182:365-8.

42. Calhoun KE, Hansen NM, Turner RR, et al. Nonsentinel node metastases in breast cancer patients with isolated tumor cells in the sentinel node: implications for completion axillary node dissection. Am J Surg. 2005;190:588-91.

43. Geertsema D, Gobardhan PD, Madsen EVE, et al. Discordance of intraoperative frozen section analysis with definitive histology of sentinel lymph nodes in breast cancer surgery: complementary axillary lymph node dissection is irrelevant for subsequent systemic therapy. Ann Surg Oncol. 2010;17:2690-5. 
44. Rutgers EJT. Sentinel node biopsy: interpretation and management of patients with immunohistochemistry-positive sentinel nodes and those with micrometastases. J Clin Oncol. 2008;26: 698-702.

45. Grube BJ, Giuliano AE. Observation of the breast cancer patient with a tumor-positive sentinel node: implications of the ACOSOG Z0011 trial. Semin Surg Oncol. 2001;20:230-7.

46. Van de Steene J, Soete G, Storme G. Adjuvant radiotherapy for breast cancer significantly improves overall survival: the missing link. Radiother Oncol. 2000;55:263-72.

47. Cserni G, Gregori D, Merletti F, et al. Meta-analysis of nonsentinel node metastases associated with micrometastatic sentinel nodes in breast cancer. Br J Surg. 2004;91:1245-52.

48. Van Zee KJ, Manasseh DM, Bevilacqua JL, et al. A nomogram for predicting the likelihood of additional nodal metastases in breast cancer patients with a positive sentinel node biopsy. Ann Surg Oncol. 2003;10:1140-51.

49. Van la Parra RF, Ernst MF, Bevilacqua JL, et al. Validation of a nomogram to predict the risk of nonsentinel lymph node metastases in breast cancer patients with a positive sentinel node biopsy: validation of the MSKCC breast nomogram. Ann Surg Oncol. 2009; 16:1128-35.

50. Cabanes PA, Salmon RJ, Vilcoq JR, et al. Value of axillary dissection in addition to lumpectomy and radiotherapy in early breast cancer. The Breast Carcinoma Collaborative Group of the Institute Curie. Lancet. 1992;339:1245-8.

51. De Boer M, van Deurzen CH, van Dijck JA, et al. Micrometastases or isolated tumor cells and the outcome of breast cancer. $N$ Engl J Med. 2009;361:653-63.

52. Buchholz TA, Hunt KK, Whitman GJ, et al. Neoadjuvant chemotherapy for breast carcinoma. Multidisciplinary considerations of benefits and risks. Cancer. 2003;98:1150-60.

53. Kuerer HM, Newman LA, Budzar AU, et al. Pathologic tumor response in breast following neoadjuvant chemotherapy predicts axillary lymph node status. Cancer J Sci Am. 1998;4:230-6.

54. Charfare H, Limongelli S, Purushotham AD. Neoadjuvant chemotherapy in breast cancer. Br J Surg. 2005;92:14-23.

55. Vlastos G, Mirza NQ, Lenert JT, et al. The feasibility of minimally invasive surgery for stage IIA, IIB, and IIIA breast carcinoma patients after tumor downstaging with induction chemotherapy. Cancer. 2000;88:1417-24.

56. Kuerer HM, Sahin AA, Hunt KK, et al. Incidence and impact of documented eradication of breast cancer axillary lymph node metastases before surgery in patients treated with neoadjuvant chemotherapy. Ann Surg. 1999;230:72-78.

57. Chung MA, DiPetrillo T, Hernandez S, et al. Treatment of the axilla by tangential breast radiotherapy in women with invasive breast cancer. Am J Surg. 2002;184:401-2.

58. Rabinovitch R, Ballonoff A, Newman F, Finlayson C. Evaluation of breast sentinel lymph node coverage by standard radiation therapy fields. Int J Radiat Oncol Biol Phys. 2008;70:1468-71.

59. Veronesi U, Orecchia R, Zurrida S, et al. Avoiding axillary dissection in breast cancer surgery: a randomized trial to assess the role of axillary radiotherapy. Ann Oncol. 2005;3:383-8.

60. Van Wely BJ, Teerenstra S, Schinagl DA, et al. Systematic review of the effect of external beam radiation therapy to the breast on axillary recurrence after negative sentinel lymph node biopsy. Br J Surg. 2011;98:326-33.

61. Voogd AC, Nielsen M, Peterse JL, et al. Differences in risk factors for local and distant recurrence after breast-conserving therapy or mastectomy for stage I and II breast cancer: pooled results of two large European randomized trials. J Clin Oncol. 2001;19:1688-97.

62. Fisher B, Montague E, Redmond C, et al. Comparison of radical mastectomy with alternative treatments for primary breast cancer: a first report of results from a prospective randomized clinical trial. Cancer. 1977;39:2827-39.

63. Whelan TJ, Olivotto I, Ackerman I, et al. NCIG-CTG MA.20: an intergroup trial of regional nodal irradiation in early breast cancer. Paper presented at: ASCO annual meeting, 2011.

64. Jakub JW, Bryant K, Huebner M, et al. The number of axillary lymph nodes involved with metastatic breast cancer does not affect outcome as long as all disease is confined to the sentinel lymph nodes. Ann Surg Oncol. 2011;18:86-93.

65. Giuliano AE, Hunt KK, Ballman KV, et al. Axillary dissection vs no axillary dissection in women with invasive breast cancer and sentinel node metastasis: a randomized clinical trial. JAMA. 2011;305:569-75.

66. Morrow M, Giuliano AE. To cut is to cure: can we really apply Z11 in practice? Ann Surg Oncol. 2011;18:2413-5.

67. Cody HS 3rd, Houssami N. Axillary management in breast cancer: what's new for 2012? Breast. 2012;21(3):411-5.

68. Cody HS 3rd. SLN biopsy for large and/or multicentric breast cancers: should we worry? Eur J Surg Oncol. 2011;37:386-7. 